\title{
Down syndrome: the aggravation of COVID-19 may be partially justified by the expression of TMPRSS2
}

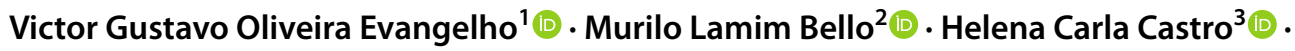 \\ Marcia Rodrigues Amorim ${ }^{4} \mathbb{0}$
}

Received: 6 October 2021 / Accepted: 30 October 2021 / Published online: 10 November 2021

(c) Fondazione Società Italiana di Neurologia 2021

\section{Dear Editor in Chief,}

We would like to highlight the article COVID-19 in patients with Down syndrome, published by Emami et al. [1] and reinforce the importance of priority vaccination in individuals with Down syndrome. COVID-19 vaccines have been developed and are continually evaluated not only in countries that have already prioritized individuals with this condition but also in nations that do not have such guidelines. At this time, countries have experienced unequal access to vaccines and are struggling to vaccinate their population but are still starting the path to wide vaccination coverage [1].

Initially, it is important to draw attention to a possible genetic factor for the higher risk of these individuals. Since the beginning of the pandemic, it has been known that SARS-CoV-2 uses the ACE2 receptor to invade and replicate in the intracellular environment, as does SARS$\mathrm{CoV}-1$. More specifically, the spike surface glycoprotein of SARS-CoV-2 interacts via the RBD domain with the human ACE2 protein. This process is mediated by the TMPRSS2 (transmembrane serine protease 2) receptor-dependent interaction, which is implicated in the priming of the SPIKE

Marcia Rodrigues Amorim

marciaamorim@id.uff.br

1 Pós-Graduação Em Ciências E Biotecnologia, Universidade Federal Fluminense, Niterói, Rio de Janeiro, Brazil

2 Laboratório de Planejamento Farmacêutico E Simulação Computacional, Departamento de Fármacos E

Medicamentos, Universidade Federal Do Rio de Janeiro, Rio de Janeiro, Brazil

3 Laboratório de Antibiótico, Bioquímica, Ensino E Modelagem Molecular, Instituto de Biologia, Universidade Federal Fluminense, Niterói, Rio de Janeiro, Brazil

4 Laboratório de Genética Humana, Instituto de Biologia, Universidade Federal Fluminense, Campus do Gragoatá, Bloco M, São Domingos, Niterói, Rio de Janeiro, RJ CEP 24201-201, Brazil protein located on the cell membrane, allowing the SPIKE protein to interact with the ACE2 receptor. In a recent study, results indicated that this gene is one of those responsible for viral infection [2]. This mechanism enables the adhesion, fusion, and finally the denudation that will start the viral replication process [3].

Interestingly, the TMPRSS2 gene is located on chromosome $21 \mathrm{q} 22.3$, thus indicating potential overexpression in individuals with Down syndrome. At the molecular level, the protein encoded from this gene is related to increased TMPRSS2 receptors. Thus, it is reasonable to think that the more severe cases of COVID-19 in these individuals may be partially explained by this contribution. Investigations in Down syndrome patients can take a step closer to understand mechanisms underlying the infectious process in COVID-19, allowing the understanding and targeting of better treatments for severe cases in the general population.

In addition to clinical indicators, neuropsychological manifestations should be taken into account in these patients, although they were not identified in the patient sample analyzed, given that both ACE2 and TMPRSS 2 are expressed in central nervous system cells. One possibility raised indicates that the olfactory bulb may be a gateway for SARS-CoV-2 into the central nervous system. In this mouse model, it was found that infection occurs via transneuronal penetration of the olfactory bulb, which may indicate the same process in humans [4].

Emami et al. [1] bring important data on the evolution of the clinical picture triggered by SARS-CoV-2 in patients with trisomy 21 and the complications when compared to typical patients. Individuals with Down syndrome have an increased risk of hospitalization, bacterial infections, and severe symptoms. Compared to the general population, these individuals have three times higher risk of death at age 40 or older [5], which reinforces that vaccines are extremely important in preventing or minimizing complications in severe cases of the disease. 
Therefore, the molecular aspects could help to identify individuals at unusually high risk, generate hypotheses, contribute to global knowledge of SARS-CoV-2 disease, and then collaborate with future research justifying issues in partnership with genomic analysis such as a possible susceptibility of a specific variant (Alpha, Beta, Gamma, and Delta) in these individuals, considering the mutations that occur in the SPIKE protein and its possible affinity with the ACE2 and TMPRSS2 proteins.

\section{Declarations}

Ethical approval Not applicable.

Conflict of interest The authors declare that they have no conflict of interest.

\section{References}

1. Emami A, Javanmardi F, Akbari A, Asadi-Pooya AA (2021) COVID-19 in patients with Down syndrome. Neurol Sci 42:1649 1652. https://doi.org/10.1007/s10072-021-05091-8
2. Sungnak W, Huang N, Bécavin C et al (2020) SARS-CoV-2 entry factors are highly expressed in nasal epithelial cells together with innate immune genes. Nat Med 26:681-687. https://doi.org/10. 1038/s41591-020-0868-6

3. Hoffmann M, Kleine-Weber H, Schroeder S et al (2020) SARSCoV-2 cell entry depends on ACE2 and TMPRSS2 and is blocked by a clinically proven protease inhibitor. Cell 181:271-280.e8. https://doi.org/10.1016/j.cell.2020.02.052

4. McQuaid C, Brady M, Deane R (2021) SARS-CoV-2: is there neuroinvasion? Fluids Barriers CNS 18:1-21. https://doi.org/10. 1186/s12987-021-00267-y

5. Hüls A, Costa ACS, Dierssen M et al (2021) Medical vulnerability of individuals with Down syndrome to severe COVID-19-data from the Trisomy 21 Research Society and the UK ISARIC4C survey. EClinicalMedicine 33:100769. https://doi.org/10.1016/j. eclinm.2021.100769

Publisher's note Springer Nature remains neutral with regard to jurisdictional claims in published maps and institutional affiliations. 